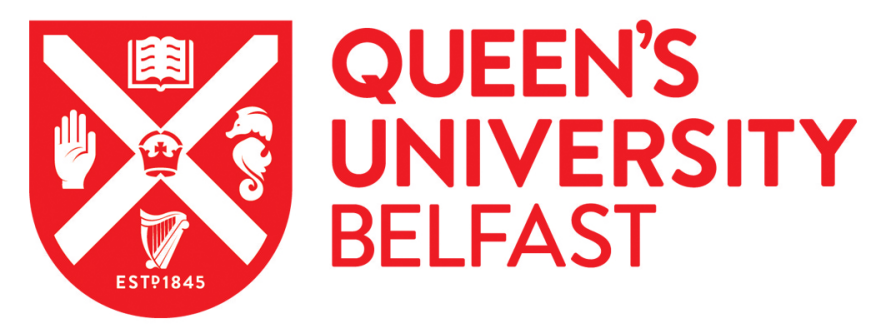

\title{
Detecting Voids within a Historical Building Façade: A Comparative Study of Three High Frequency GPR Antenna
}

Johnston, B., Ruffell, A., McKinley, J., \& Warke, P. (2018). Detecting Voids within a Historical Building Façade: A Comparative Study of Three High Frequency GPR Antenna. Journal of Cultural Heritage, 32, 117-123.

https://doi.org/10.1016/j.culher.2018.02.003

Published in:

Journal of Cultural Heritage

Document Version:

Peer reviewed version

Queen's University Belfast - Research Portal:

Link to publication record in Queen's University Belfast Research Portal

Publisher rights

(C) 2018 Elsevier Masson SAS

This manuscript version is made available under the CC-BY-NC-ND 4.0 license http://creativecommons.org/licenses/by-nc-nd/4.0/,which permits distribution and reproduction for noncommercial purposes, provided the author and source are cited.

\section{General rights}

Copyright for the publications made accessible via the Queen's University Belfast Research Portal is retained by the author(s) and / or other copyright owners and it is a condition of accessing these publications that users recognise and abide by the legal requirements associated with these rights.

Take down policy

The Research Portal is Queen's institutional repository that provides access to Queen's research output. Every effort has been made to ensure that content in the Research Portal does not infringe any person's rights, or applicable UK laws. If you discover content in the Research Portal that you believe breaches copyright or violates any law, please contact openaccess@qub.ac.uk. 
Detecting Voids within a Historical Building Façade: A Comparative Study of Three High Frequency GPR Antenna

\author{
Brian Johnston ${ }^{1}$, Alastair Ruffell ${ }^{1}$, Jennifer McKinley ${ }^{1}$ and Patricia Warke ${ }^{1}$ \\ [1] School of the Natural and Built Environment, Queen's University Belfast, Belfast, UK, BT7 1NN

\section{Correspondence to BJohnston16@qub.ac.uk}

Keywords: Ground Penetrating Radar, Urban Weathering, Sandstone, Non-destructive survey, Frequency Comparison, Reflection Profiles

\title{
Word Count: 3311
}

\section{Abstract}

Ground penetrating radar is becoming an established component of the stone conservation researcher's arsenal. There is great potential in this quick and non-destructive technique that provides confirmation of deterioration features, such as voids, whose presence has been suggested using other tools. The past application of this technology has focused upon block scale stone deterioration, with less attention given to the study of features that extend across multiple blocks within the walls. The aim of this paper was to primarily to demonstrate the suitability of GPR for identifying void spaces when run across a rough surfaced wall façade. Additionally, this work aims to aid in the application of GPR for this purpose, by providing a comparison of three commonly used antennas to inform equipment choice during survey design.

For this study, three high frequency antennas, $1.2 \mathrm{GHz}, 1.6 \mathrm{GHz}$ and $2.3 \mathrm{GHz}$, were run along the same perpendicular test lines across multiple blocks within a historical building façade. The resultant reflection profiles demonstrated that GPR can identify the presence of features within the blocks when run across a rough wall section. However, without the use of additional information from secondary data sources it is not possible to confirm the identity of features. The comparison of the three antennas, showed that the $1.6 \mathrm{GHz}$ antenna was the least suited for this task, due to the presence of extensive ringing in the resultant reflection profiles. Alternatively, the $1.2 \mathrm{GHz}$ antenna is most suitable for investigations deep within the wall and the $2.3 \mathrm{GHz}$ better suits highly detailed analysis of features present within the near surface material. The choice of the most appropriate antenna depends upon the nature of the task it will be deployed for.

\section{Introduction}

Weathering processes will result in the alteration of stone, both as part of a natural outcrop or emplaced within the façade of a building [1]. Previous attempts to monitor the extent of these changes 
across historic structures has led to the inclusion of multiple tools into the researcher's 'toolbox' [2]. However, due to the cultural significance often associated with these structures, it is preferable that non-destructive techniques are used [3]. Ground penetrating radar (GPR) is one such tool, that is now used widely by geomorphologists, civil engineers and conservationists $[4,5]$. The use of high frequency (typically above $1 \mathrm{GHz}$ ) GPR allows the visualisation of shallow (tens of centimetres) subsurface structures, such as voids or areas of weakened material in buildings and structures [6].

One of the main applications for GPR in weathering studies is the confirmation of features that other techniques suggest are present [7]. Identification of these subsurface features can be difficult, particularly when using non-destructive techniques, as indication of their presence does not always match the reality [7]. GPR therefore serves an important verification purpose, locating features such as voids or areas of weakness, through the observation of features upon the resultant reflection profiles or 'radargrams'. Whilst GPR literature commonly uses the term 'reflection profile' [4], stone weathering studies refer to the such 2D slices into the ground or (in this case) wall as 'radargram(s)'. The application of GPR for this purpose within historical masonry walls tends to be limited to singular 'important' stones within the walls [8]. However, the treatment of walls as a series of individual blocks rather than as a combined whole, ignores the existence of observed deterioration features extending beyond the extent of the block scale.

\section{Research Aims}

The first aim of this paper is to demonstrate the potential of GPR in identifying voids and features when running across multiple blocks emplaced within a wall. The second aim of the paper relates to the methodology of applying GPR. Using GPR as part of weathering studies requires the selection of appropriate equipment, especially when referring to the frequency of the antenna. This choice will influence the depth of penetration and the size of features that can be identified by the equipment. However, the cost of GPR equipment means that most studies are restricted to selecting one or two frequencies for their work. The authors have found themselves in a unique situation where they can provide an essential comparison of three commonly used antenna frequencies. Using such a comparison, this work aims to identify strengths and weaknesses of each antenna frequency when working with weathered historic stone.

\section{GPR and Heritage Studies}

The earliest applications of GPR for cultural heritage was the identification of points of interest, such as buried structures or graves to direct archaeological digs [9]. Once the technique was established externally it was a short step to investigating internal surfaces, identifying areas of weakness or 
features beneath the flooring of historical buildings [10]. However, the name 'ground penetrating radar' can create false perceptions of the limitation of the technology as GPR is not restricted to application on the horizonal plane of the Earth's surface. It can be used to investigate the presence of variation within vertical wall sections, or even ceiling sections [11].

Frequently, GPR is used in this fashion as a non-destructive technique to complement the use of the documentary research [12]. One common example of this is locating metal support bracing within columns [12]. Application to columns has also been used to understand the complex nature of their irregular construction [13].

Application of the technique to walls was developed from both a built heritage and an engineering perspective, however, such studies declare the need for smooth surfaces to run the equipment over $[14,15]$. As a result, there are multiple studies showing the application of GPR to detect deterioration within concrete retaining walls [16], behind plaster covered surfaces [17] or within regularly finished masonry surfaces [18]. Attempts to apply the technique for the investigation of block walls with irregular surfaces remain absent from the literature.

The investigation of individual stones within block walls using GPR has become a well-established technique since the early 1990s, due to the convenience and speed of application $[8,19]$. These studies advocate the potential of the technique for the detection of altered material within the weathering layers or the presence of voids and cracks within blocks. According to Lindsay et al. [2], cracks cannot be detected when using a $1.6 \mathrm{GHz}$ antenna unless they correlate to a void space. However, they suggest that through the application of a $2.3 \mathrm{GHz}$ antenna visualisation of cracks may be possible. This example illustrates the importance of appropriate equipment selection based upon the scale of the feature that needs to be observed.

Recent 3D and 2D GPR surveys have shown the potential of the technology to identify weaknesses when applied beyond the block extent [18]. Implementation of the findings of such studies can now drive forward the application of 2D and 3D GPR to more complex walls. GPR is also considered to be part of non-destructive, monitoring toolsets, tracking the presence of potentially damaging moisture and salts within wall sections [20].

Despite the range of applications presented here there remains no comparative analysis of high frequency antennas. It should be noted that some comparison studies do exist between medium to high $(800 \mathrm{MHz})$ and high frequency antennas $(1600 \mathrm{MHz})$ [18]. Given the influence that this can have upon the findings and the importance that these studies may have upon future conservation campaigns, it is essential that a comparative study is undertaken [6]. 


\section{Study Site}
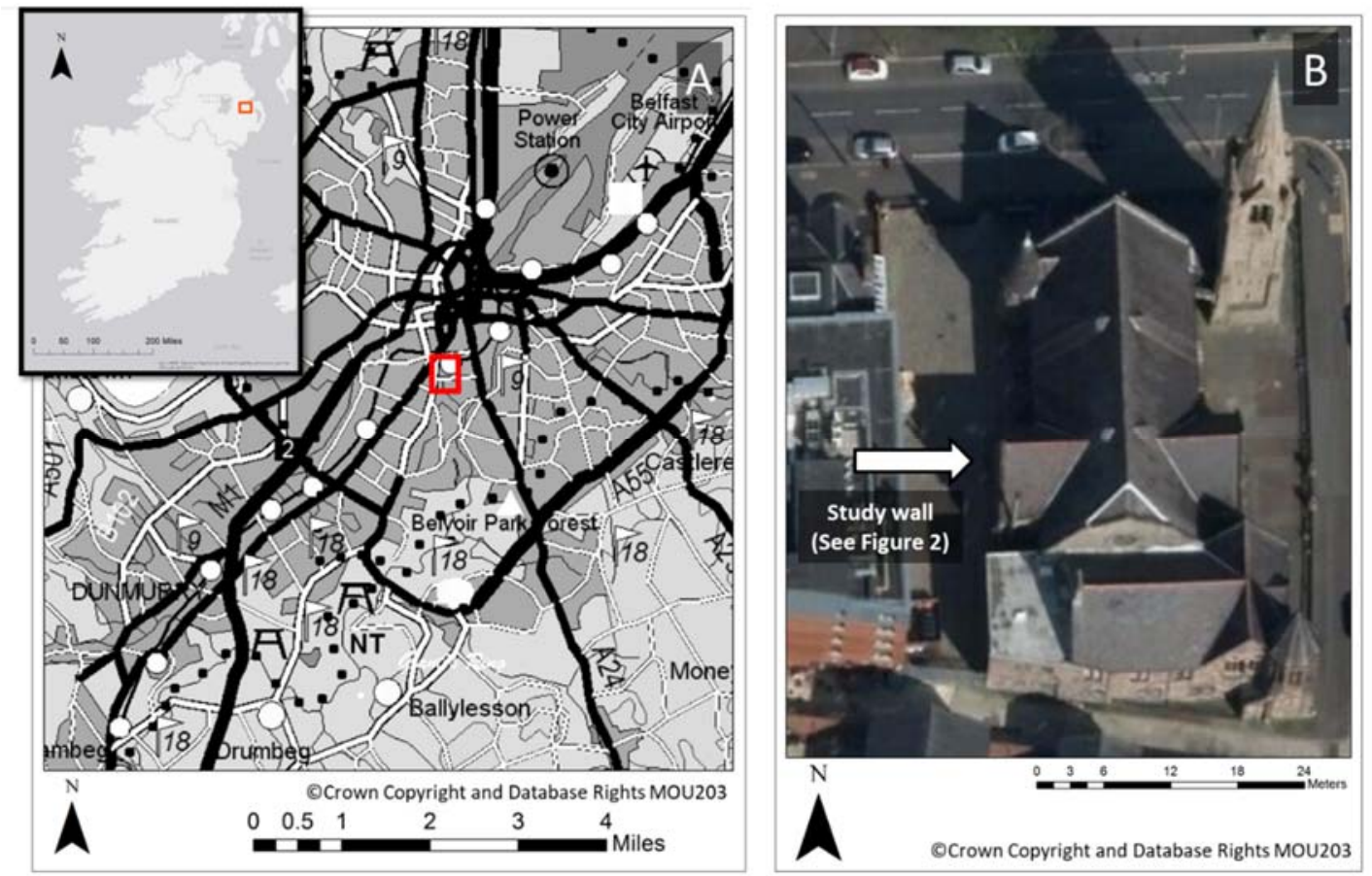

Figure 1

(A) Location of Fitzroy Presbyterian church within Ireland and Belfast, and (B) the location of the study wall section on the building.

The selected study site for this work was a wall section of Fitzroy Presbyterian Church in the south of Belfast, N. Ireland (UK). The church was constructed between 1872 and 1874 to meet the demands of an expanding population during the industrialisation of the city. The walls of the church are rubble filled stone walls. Despite clean air legislation, high levels of pollutants and atmospheric particulates remain in Belfast due to domestic sources and temperature inversions created by the topographic setting [21]. In the 1980s the north façade and tower of the church underwent a conservation campaign of chemical cleaning and repointing [22]. The results of this campaign were considered disastrous, due to the accelerated biological growth, and cleaning was abandoned before it was implemented across the remain façades. Repointing was undertaken across the remaining façades, though it should be noted that damage to the neighbouring stones due to the aggressive removal of the original mortar was noted [22].

The chosen wall is approximately $36-40 \mathrm{~cm}$ thick, with the surface $16 \mathrm{~cm}$ constructed from blocks of Scrabo Sandstone, a local Triassic quartzose sandstone. The remaining thickness of the wall is constructed of unsorted rubble. Scrabo's depositional environment was fluvial with periods of aeolian activity, resulting in well-defined bedding planes and laminations [23]. It also resulted in the presence 
of mud rip up clasts in blocks that were noted within the stone blocks. Several decay features are visually present on the surface of the wall, including granular disintegration, delamination and flaking. Past inspection of the distribution of weathering features suggested interconnectivity between blocks or the presence of voids, making it an ideal candidate for an exploratory GPR survey [24].

The wall section has two sections of decorative sandstone string course running across the surface, one at $0.6 \mathrm{~m}$ from ground level and the other at $1.2 \mathrm{~m}$. The rest of the blocks have been given an architecturally roughened finish prior to emplacement. The combination of this roughness and the presence of weathering features results in a surface that would prove difficult to smoothly move the GPR equipment across.

\section{Methodology}

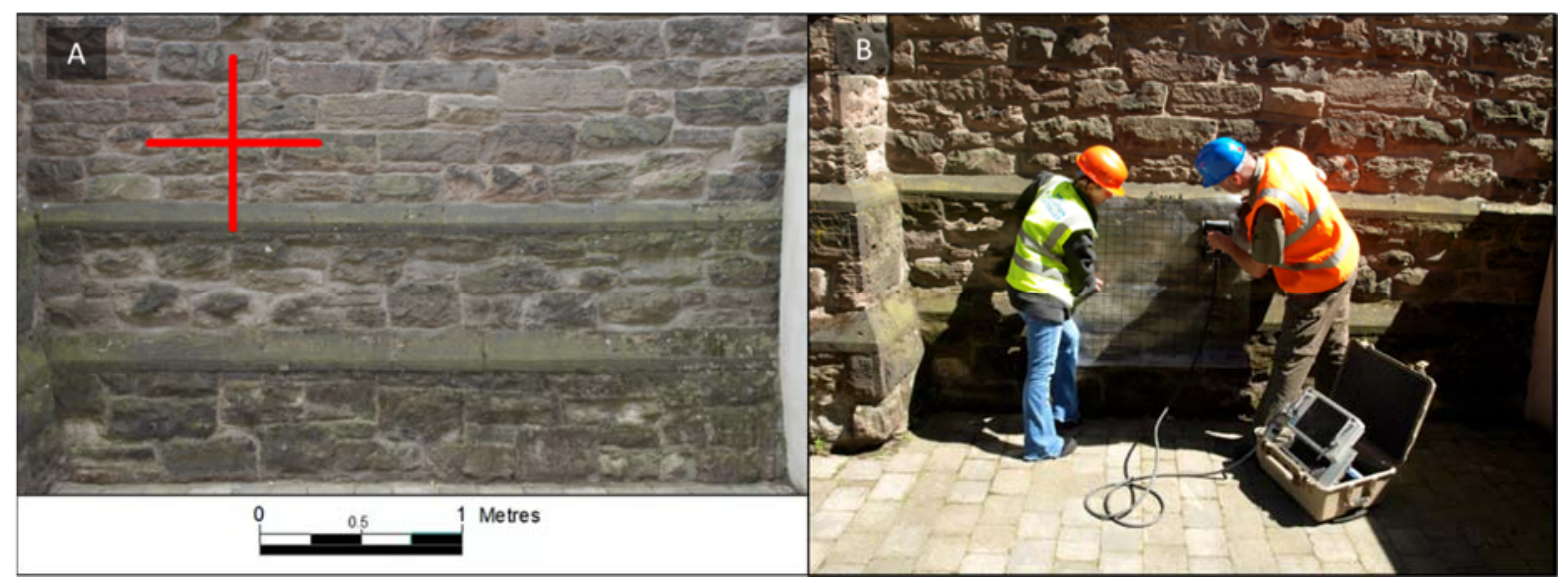

Figure 2

(A) Location of the perpendicular test lines, marked in red, on the study wall surface (B) Operation of the equipment on the study wall section.

\subsection{GPR}

GPR uses high frequency electromagnetic energy pulses in the frequency of radio waves to detect changes in the surveyed medium [6]. Dielectric permittivity controls the velocity at which such waves move through any medium (such as stone): when changes occur, the wave maybe refracted or reflected, indicating a change in the nature of the subsurface. The reflection of radar waves occurs where objects or layers are encountered that possess different electrical properties to the surrounding or overlying medium [25]. A typical GPR system requires a transmitting and receiving antenna to generate the wave (or signal), and record it's reflection. Using the two-way travel time (TWT), the time between the generation of the radar wave and its reception back at the surface after reflecting off the 
subsurface discontinuity, and the propagation velocity it is possible to calculate the depth of an identified feature [6].

Choice of the antenna frequency is an important component when designing a survey strategy, influencing the resolution of the output and the depth of penetration [26]. Waves of a lower frequency will penetrate deeper into the material, as they are not as easily attenuated as high frequency waves [6]. However, these lower frequency antennas are unable to resolve smaller features within the medium. The result of these differences is the requirement that a balance is struck between the need for depth penetration and the demand for finer resolution observations.

\subsection{Data Collection}

Prior to data collection, a CEIA Systems compact metal detector was utilised to inspect the study wall, checking for imbedded metal work. The detector was run using both high and low frequencies confirming the absence of metal within the wall, at shallow and deep penetrations.

The three antennas used in this study were $1.2 \mathrm{GHz}, 1.6 \mathrm{GHz}$ and $2.3 \mathrm{GHz}$ manufactured by Malå Geoscience (Sweden). They were each run along two perpendicular test lines of approximately $80 \mathrm{~cm}$ in length. The data was logged along the vertical line from top to bottom, whilst horizontal data was logged from the left to right of the wall section. Given the rough surface of the wall, the manufacturer supplied plastic sheet, sized $80 \mathrm{~cm} \times 80 \mathrm{~cm}$, was attached to the wall. The GPR antennas were mounted on a wheel cart that controlled the data logging and with the smoother surface created by the plastic sheeting, created a more continuous output. We ran repeat experimental lines along relatively smooth areas, without the plastic sheet, and then with the plastic sheet. This was to examine whether the $0.5 \mathrm{~cm}-1 \mathrm{~cm}$ air gaps that were introduced by the sheet would have any effect on data quality. As differences were negligible, the plastic sheet was deployed.

\subsection{Processing}

The data was processed post collection within Malå Groundvison (v.1.26.1, registered download of free software) with the application of DC adjustment to all reflection profiles [27]. DC Adjustment removes DC drift and shifts the signal back to the zero line [28]. Background removal was undertaken using Groundvision's FIR (Finite Impulse Response) filter, a quick band-pass filter. Hyperbola matching for velocity interpretation was carried out using Sandmeier's ReflexW Programme (Licence 401, Queen's University Belfast).

\section{Results and Interpretation}


The resulting reflection profiles from the horizontal test lines can be found in Figure 3 while the vertical test lines can be found in Figure 4.

\subsection{Horizontal Test Line}

The horizontal test line runs across three stones identified here as $\mathrm{H} 1, \mathrm{H} 2$ and $\mathrm{H} 3$ (Figure 3). The 1.2 $\mathrm{GHz}$ antenna identifies two layers, a stone layer, relating to the thickness of the block, and the rubble layer, where the pulse has penetrated through to the rubble fill. The interface between these layers is at $16 \mathrm{~cm}$. This depth is at the limitation of the pulse penetration for the $2.3 \mathrm{GHz}$ antenna and thus the interface is not apparent within the resulting radargram.

A

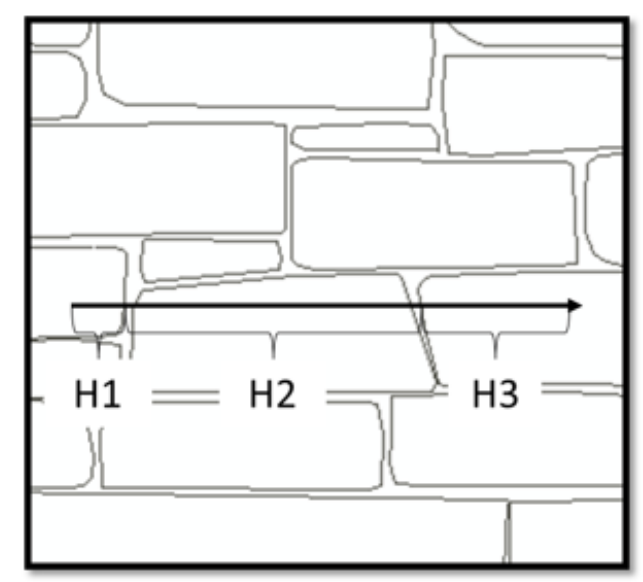

C

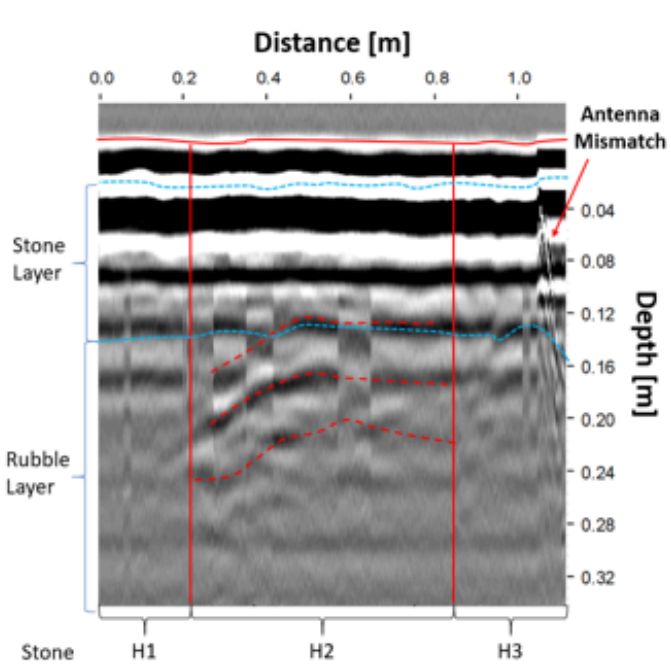

B

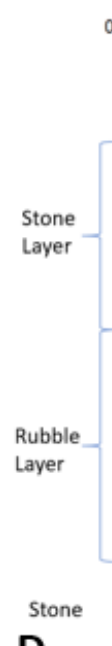

D
1.2Ghz Antenna
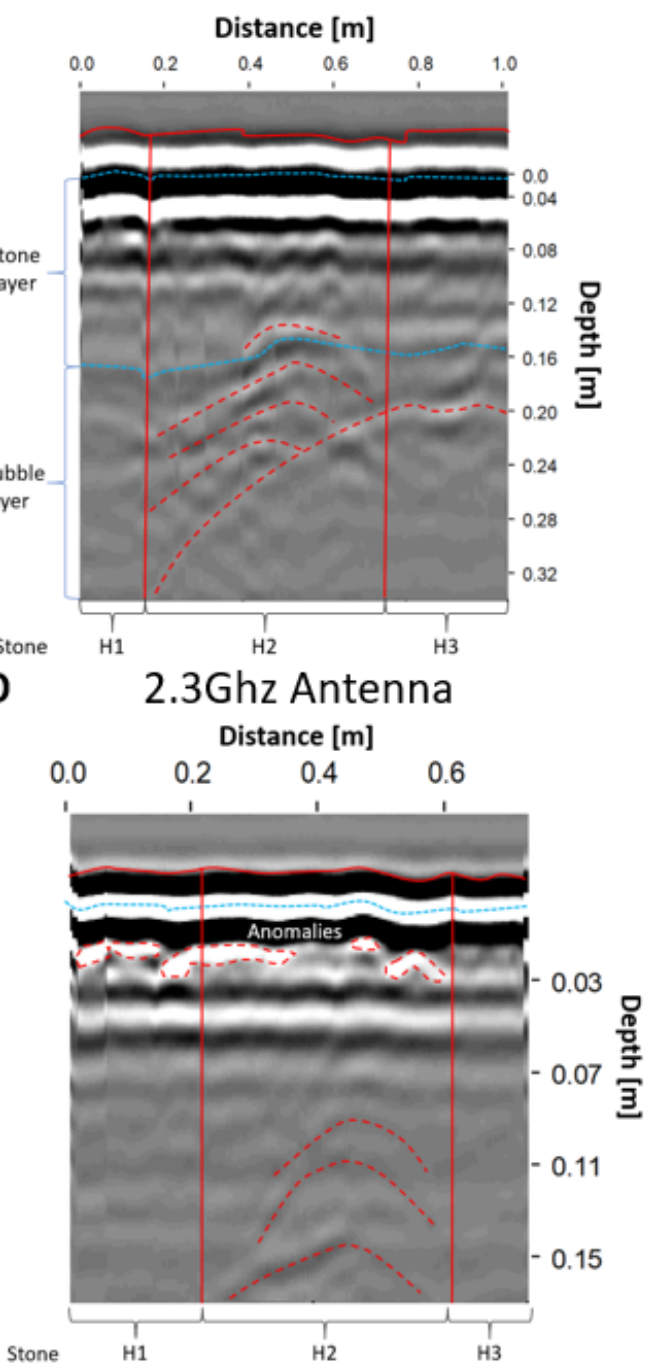

Figure 3

Annotated reflection profiles produced from running the three different frequencies of antennas, $1.2 \mathrm{GHz}(B), 1.6 \mathrm{GHz}(C)$ and $2.3 \mathrm{GHz}(D)$, along the horizontal testline $(A)$. 
The ringing observed in the $1.6 \mathrm{GHz}$ radargram is not visible on the other two reflection profiles. Ringing occurs when signals from the GPR reverberate in regular fashion as they repeatedly bounce within the antenna [29]. The application of a background removal filter partially removed this feature however it did not eliminate it. The $1.6 \mathrm{GHz}$ radargram also shows the presence of a zone of antenna mismatch, also known as a coupling error.

Within the stone layer, using the $1.6 \mathrm{GHz}$ and the $2.3 \mathrm{GHz}$ antenna, there is a hyperbolic reflection identified at approximately $12 \mathrm{~cm}$ depth within stone $\mathrm{H} 2$. Hyperbola fitting to calculate velocity in ReflexW showed this feature to be consistent with an air void, as opposed to other objects like mud clasts. A similar feature is also identified within $\mathrm{H} 2$ using the $2.3 \mathrm{GHz}$ antenna at $8 \mathrm{~cm}$. The $2.3 \mathrm{GHz}$ antenna reflection profile also shows a group of near surface anomalies at approximately $2 \mathrm{~cm}$ depth.

\subsection{Vertical Test Line}

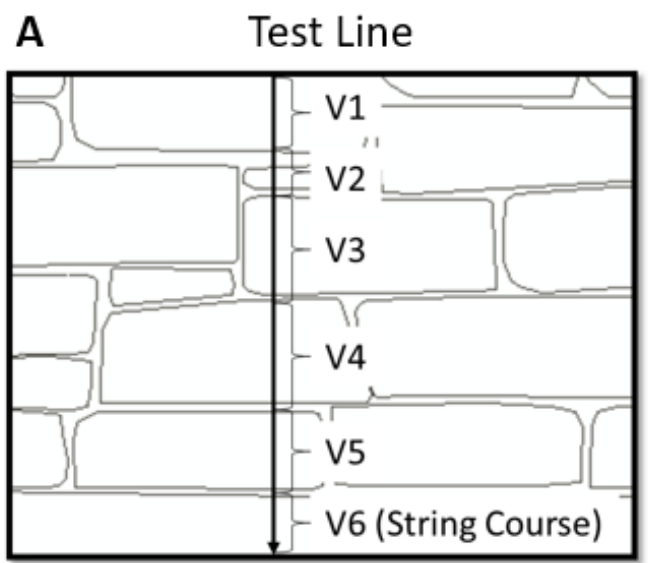

D

$$
\text { C }
$$

1.6Ghz Antenna

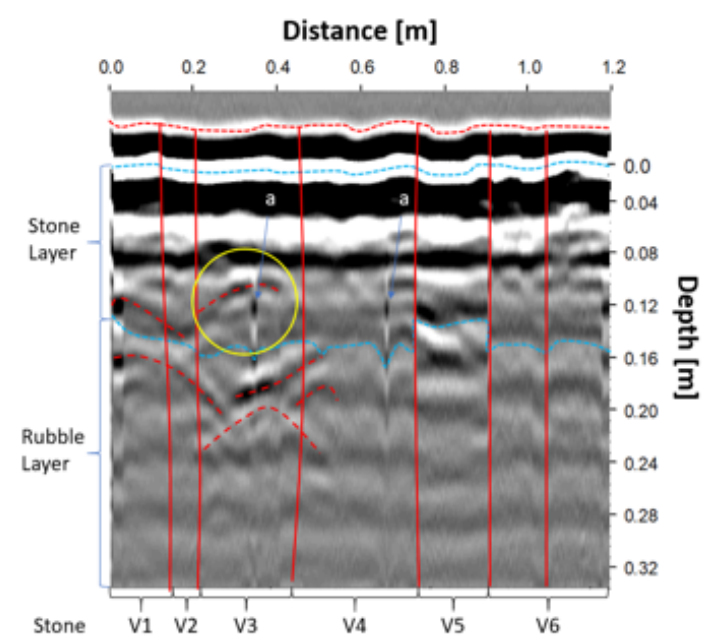

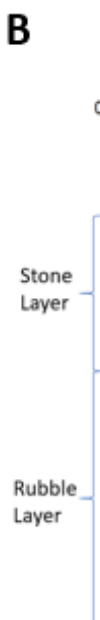

Stone

1.2Ghz Antenna

Distance [m]

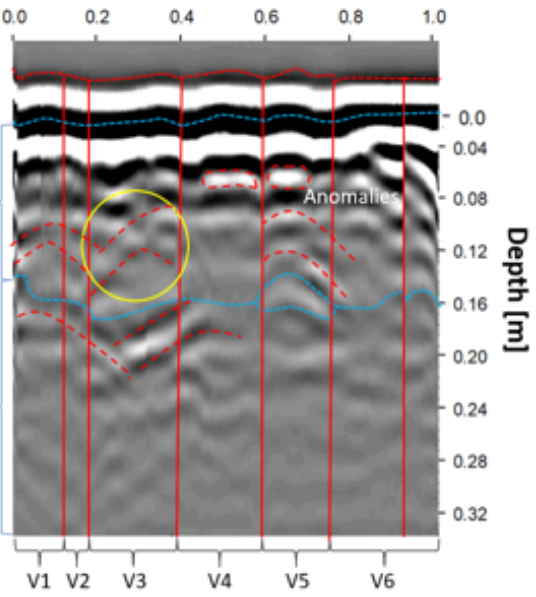

2.3Ghz Antenna

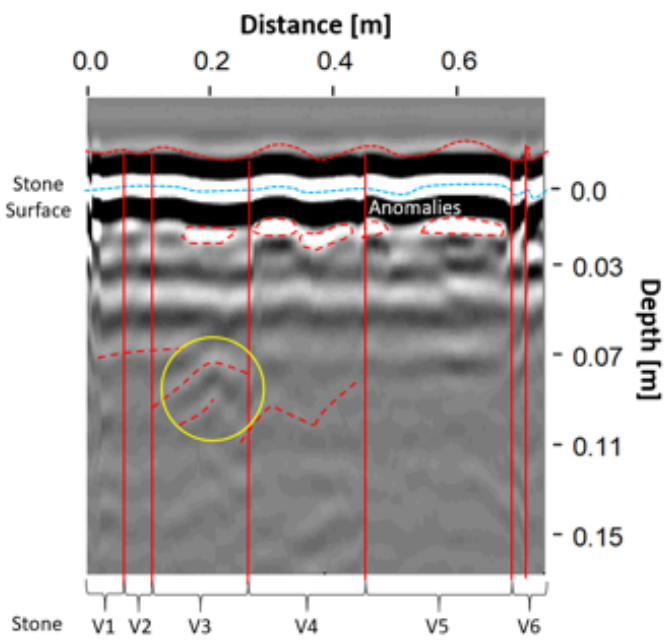

Figure 4 
Annotated reflection profiles produced from running the three different frequencies of antennas, $1.2 \mathrm{GHz}(B), 1.6 \mathrm{GHz}(C)$ and $2.3 \mathrm{GHz}(D)$, along the vertical test line (A). Artefacts detected on the $1.6 \mathrm{GHz}$ radargram are marked with an ' $a$ '.

The vertical test line runs across six stones identified here as V1 to V6, as shown in Figure 4. As with the horizontal lines, two identifiable layers are present in the $1.2 \mathrm{GHz}$ reflection profiles, the stone and rubble layers. The interface can be found at $16 \mathrm{~cm}$ depth, as observed with the horizontal test lines. The radargram produced using the $2.3 \mathrm{GHz}$ antenna identified a series of anomalies in the near surface $(0-3 \mathrm{~cm}$ depth). The reflection profiles all identify the presence of the stringcourse (block V6) as they pass over the top of it, with the topographic change creating an anomaly in the output. Another area where the three reflection profiles agree is the identification of a feature within Block V3.

The radargram produced using the $1.6 \mathrm{GHz}$ antenna shows the strong ringing, as observed during the horizontal test lines. This would suggest that the presence of ringing is a result of the application of this version of antenna to stone wall investigations. The $1.6 \mathrm{GHz}$ radargram also identified two anomalies, however their absence from the other reflection profiles suggests that these anomalies are just artefacts from the data collection.

\section{Discussion}

\subsection{GPR for void detection}

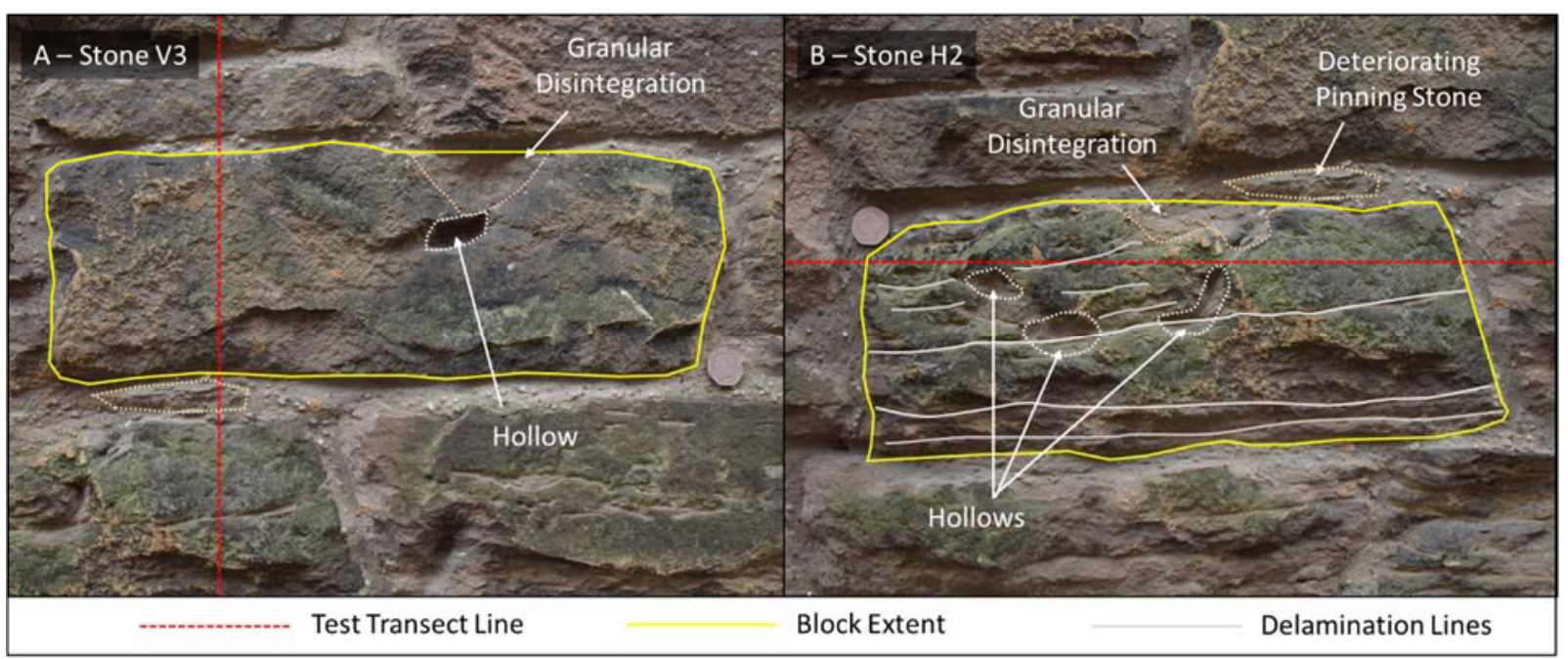

\section{Figure 5}

Annotated photos of the blocks of interest identified by the test lines, $(A)$ Vertical Block 3 and (B) Horizontal Block 2.

Previous studies (such as Laing et al. [8]) have shown GPR to be a useful tool for void detection when applied to single blocks of interest. Now the value of its application across multiple blocks within a 
building façade has been demonstrated. One of the main limitations of the technique's past application was the roughness of surfaces and the subsequent disruptions to the smooth acquisition of data. Using the plastic sheet to create the required smooth surface, it was possible to acquire data continuously, overcoming this difficulty.

Observations made using GPR have led to the identification of two stones of interest within this wall section. Firstly, stone $\mathrm{H} 2$ is identified as the location of a possible void. Visual inspection of the block surface identified the presence of surface weathering features, such as delamination, granular disintegration and hollows (Figure 5B). The return signal from the rear of this block also suggests the presence of another feature. One possible reason could be the presence of a stone type or a cavity with a different velocity than Scrabo Sandstone.

The other block of interest is V3. As all the vertical reflection profiles from the three frequencies identified the presence of a feature, it is likely present within the block. It is not possible to say with certainty what the feature is, however, it is possible to make an educated guess based upon visual observations at the site (Figure 5A). One possibility relates to the presence of the hollow on the wall surface, where a clay rip-up clast has been detached from the block. If other such rip-up clast exists within the stone, then it could be the feature identified by the radargram. This has validity as long as there is difference in dielectric permittivity between the sandstone and any clay clasts contained within; which are likely to be significant and thus cause a strong reflection. Alternatively, the feature is situated near to the edge of the block, where a small pinning stone that is visually deteriorating is located. The final possibility is the presence of a void either within the block or mortar, the presence of which may have been exasperated by the deteriorating pinning stone or a rip-up clast.

Finally, the near surface anomalies identified when using the $2.3 \mathrm{GHz}$ antenna, may be the result of small voids within the stone. Alternatively, their origin may be the result of the development of fine cracks and weaknesses associated with the initiation of contour scaling. Their depth matches with the development of such features, observed during a simulation study by Smith and McGreevy [30].

Interpretation of reflection profiles requires an experienced operator to identify the presence of features [6]. As a tool it is best suited to complement other techniques or to confirm suspected features. Where multiple techniques confirm the presence of a feature then the investigator trust the findings with some degree of certainty.

\subsection{Comparing the Frequencies}

The presence of ringing limits the value of the output radargram produced using the $1.6 \mathrm{GHz}$ antenna. The presence of this artefact for the runs along both the horizontal and the vertical test lines implies 
that the source of the issue remains consistent, either the manufacture of the equipment or the choice of frequency. The equipment has since be deployed as a part of other projects where it has performed flawlessly, suggesting that the issue may be a result of the choice of frequency.

The other antennas' performance as part of this work was as expected. The $1.2 \mathrm{GHz}$ antenna achieved a deep penetration $(32 \mathrm{~cm})$ into the wall identifying the interface between the stone layer and the rubble fill, yet it had limited effect identifying the presence of detailed features. All frequencies were attenuated by the stone and (inferred) rubble layer, limiting deeper penetration into the wall. The 2.3 $\mathrm{GHz}$ did not penetrate to the depth of the interface between the layers but it can identify small void features that the $1.2 \mathrm{GHz}$ was not able to distinguish.

Based upon the findings of this study, the authors found the $1.2 \mathrm{GHz}$ proved itself to be the most suitable for identifying the general status of the stones within the wall. This would make it a beneficial tool to support conditional surveys of historical facades. Alternatively, the $2.3 \mathrm{GHz}$ is better suited for confirming the presence of small scale features within the wall such as voids. It is therefore a better choice for targeted work, confirming the presence of features previously identified using other techniques. The choice of antenna is highly dependent upon the purpose of the study.

\section{Conclusions}

- GPR has proven to be quick and non-destructive method to provide confirmation of the presence of deterioration features or voids within historical building facades.

- In the case of Fitzroy Presbyterian Church, it has successfully identified a series of possible void features within the walls.

- Where uncertainty exists relating to the identity of the features then future work is needed to consider linking the presence of anomalies with additional datasets such as LiDar, X-ray [31], thermal imaging [7] and ultrasonic [32, 33].

- The $1.2 \mathrm{GHz}$ antenna was proven as a tool for investigations deep within the wall, whilst the $2.3 \mathrm{GHz}$ demonstrated a capacity for providing highly detailed analysis of the features present within the near surface material.

- The presence of strong ringing in the output reflection profiles generated by the $1.6 \mathrm{GHz}$ antenna in this setting, suggests that this frequency is not suitable for undertaking GPR investigations of wall sections.

- Choosing the appropriate antenna frequency depends upon the nature of the task for which it is being deployed.

\section{Acknowledgements}


The authors would like to express their appreciation for the receipt of the Soulby Research Grant 2017, a PGR student prize, that funded the project from which this research was derived. They would also like to thank the congregation of Fitzroy Presbyterian Church for allowing unrestricted access to their place of worship. Appreciation is also due to Mike Langton of Mala Geoscience and Marty Hamilton of Sigma Solutions for their assistance in providing the $1.2 \mathrm{GHz}$ and $2.3 \mathrm{GHz}$ antennas used for this study. Finally, the authors need to thank individuals who assisted during this project's field work, $\mathrm{Dr}$ Lisa Coyle-McClung, Dr David Bell and Max Meulendijks.

\section{References}

[1] Yatsu, E. (1988) The Nature of Weathering: an introduction, Sozosha: Tokyo

[2] Lindsay, C., Smith, B., Curran, J., McKinley, J., Meneely, J., Ruffell, A., Savage, J. and Stelfax, D. (2010) "An Integrated Toolkit for the Conservation of Stone-Built Heritage", In Geophysical Research Abstracts. vol. 12.

[3] Masini, N., Persico, R. and Rizzo, E. (2010) "Some examples of GPR prospecting for monitoring of the monumental heritage" Journal of Geophysics and Engineering, 7, 190-199

[4] Daniels, D. J. (2004) Ground penetrating radar (2nd edition), The Institution of Electrical Engineers: London.

[5] Conyers, L.B. (2013) Ground-penetrating radar for archaeology (3rd edition), AltaMira Press: Lanham.

[6] Robinson, M., Bristow, C., McKinley, J. and Ruffell, A. (2013) "1.5.5. Ground Penetrating Radar: Part 1, Sec. 5.5”, In. Geomorphological Techniques, British Society for Geomorphology: London.

[7] Kilic, G. (2015) "Using advanced NDT for historic buildings: Towards an integrated multidisciplinary health assessment strategy" Journal of Cultural Heritage, 16:4, pp.526-535.

[8] Laing, Z., Sun, J., Zhang, Z., Shao, A. and Zheng, X. (2016) "The application of non-destructive testing methods for the investigation of weathering diseases of stone relics" In, Yang, Z. and Tanimoto, C. (Eds.) Ancient Underground Opening and Preservation: Proceedings of the International Symposium on Scientific Problems and Long-term Preservation of Large-scale Ancient Underground Engineering (23-26 October 2015, Longyou, Zhejiang, China) CRC Press: London, pp.145-150.

[9] Vaughan, C. (1986) "Ground-penetrating radar surveys used in archaeological investigations." Geophysics, 51:3, pp.595-604. 
[10] Pérez Gracia, V., Canas, J. A., Pujades, L. G., Clapés, J., Caselles, O., García, F. and Osorio, R. (2000) "GPR survey to confirm the location of ancient structures under the Valencian Cathedral (Spain)" Journal of Applied Geophysics, 43: 2-4, pp. 167-174.

[11] Gracia, P., de la Vega, M., Caselles Magallón, J.O. and Clapes Boixader, J. (2017) "Ground penetrating radar assessment of historical buildings: the study of the roofs, columns and ground of Santa Maria del Mar, in Barcelona/GPR assessment of the basilica Santa Maria del Mar", In Proceedings of 2015 IEEE 15th Mediterranean Microwave Symposium (MMS), IEEE Press, pp. 498501.

[12] González-Drigo, R., Pérez-Gracia, V., Di Capua, D. and Pujades, L.G. (2008) “GPR survey applied to Modernista buildings in Barcelona: The cultural heritage of the College of Industrial Engineering" Journal of Cultural Heritage, 9, pp.196-202.

[13] Santos-Assunçao, S., Perez-Gracia, P., Caselles, O., Clapes, J. and Salinas, V. (2014) "Assessment of Complex Masonry Structures with GPR Compared to Other Non-Destructive Testing Studies" Remote Sensing, 6, pp. 8220-8237.

[14] Pajewski, L., Solla, M. and Kü ç ükdemirci, M. (2017) "Ground Penetrating Radar for Archaeology and Cultural-Heritage Diagnostics", In. Gonçalves, L., Rodrigues, H. and Gaspar F. (eds.) Non-destructive Techniques for the Assessment and Preservation of Historic Structures, CRC Press: Boca Raton.

[15] Martinho, E. and Dionísio, A. (2014) "Main geophysical techniques used for non-destructive evaluation in culutal built heritage: a review" Journal of Geophysics and Engineering, 11, pp. 1-15.

[16] Hugenschmidt, J. and Kalogeropoulos, A. (2009) "The inspection of retaining walls using GPR" Journal of Applied Geophysics, 67:4, pp. 335-344.

[17] Côte, P., Dérobert, X., Miltiadou-Fezans, A., Delinikolas, N., Durand, O., Alexandre, J., Kalagri, A., Savvidou, M., Chryssopoulos, D., Anamaterou, L. and Georganis, F. (2007) "Application of nondestructive techniques at the Katholikon of Dafni Monastery for mapping the mosaics substrata and grouting monitoring", In. D'Ayala, D. and Fodde, E. (Eds.) Structural Analysis of Historic Construction, Taylor and Francis: London, pp. 1149-1156.

[18] Ranalli, D., Scozzafava, M. and Tallini, M (2004) “Ground penetrating radar investigations for the restoration of historic buildings: the case study of the Collemaggio Basilica (L'Aquila, Italy)" Journal of Cultural Heritage, 5:1, pp.91-99. 
[19] Shi-Hang, Z. (1991) "New progress in applying geophysical exploration methods to protecting historical relics and to archeology" Acta Geophysica Sinica, 34:5, pp. 635-643.

[20] Di Tammaso, A., Gentilini, C. and Castellazzi, G. (2015) "Investigation of Damp and Salt Distribution in Outdoors Full-Scale Masonry Wall via Wireless Monitoring and Radar Testing" Key Engineering Materials, 624, pp.155-162.

[21] Smith, B. J., Whalley, W. B. and Magee, R. W. (1991) "Background and local contributions to acidic deposition and their relative impact upon building stone decay: A case study of Northern Ireland", In Longhurst, J. W. S. (Ed.) Acid Deposition: Origins, Impacts and Abatement Strategies, Springer-Verlag:Berlin, pp. 241-266.

[22] Warke, P. A., Smith, B. J. and Campbell, U. R. (1999) "Characterisation of Decay Features on Sandstone Following Cleaning: Preliminary Observations", In Jones, M. S. and Wakefield, R. D. (Eds.) Aspects of Stone Weathering, Decay and Conservation, Imperial College Press: London, pp.65-76.

[23] Buckman, J.O., Doughty, P.S., Benton, M.J. and Jeram, A.J. (1997) "Palaeoenvironmental Interpretation of the Triassic Sandstones of Scrabo, County Down, Northern Ireland: Ichnological and Sedimentological Studies Indicating a Mixed Fluviatile-Aeolian Succession" Irish Journal of Earth Sciences, 16, pp. 85-102.

[24] Johnston, B., McKinley, J., Warke, P. and Ruffell, A. (2017). “Non-Destructive Approaches for the Validation of Visually Observed Spatial Patterns of Decay". In: EGU 2017. Vienna: Copernicus, p.17236.

[25] Neal, A. (2004) "Ground Penetrating Radar and its use in sedimentology: Principles, Problems and Progress" Earth Science Reviews, 66, pp.261-300.

[26] Baker G. S., Jordan, T. E. and Pardy, J. (2007) "An introduction to ground penetrating radar (GPR)" The Geological Society of America Special Publications, 432, pp.1-18.

[27] Malå Geoscience (2011) Malå Groundvision software: Operating Manual v. 2.1., Malå Geoscience: Malå

[28] Goodman, D. and Piro, S. (2013) GPR Remote Sensing in Archaeology Springer: Berlin.

[29] Kim, J., Cho, S and Yi, M. (2007) "Removal of ringing noise in GPR data by signal processing" Geosciences Journal, 11, pp75-81.

[30] Smith, B. J. and McGreevy, J. P. (1988) Contour scaling of a sandstone by salt weathering under simulated hot desert conditions Earth Surface Processes and Landform, 13, pp.697-705. 
[31] McCann, D. N. and Forde, M. C. (2001) "Review of NDT methods in the assessment of concrete and masonry structures" NDT \& E International, 34:2, pp.71-84.

[32] Francese, R. G., Galgaro, A. and Grespan, A. (2004) "Venice channel side-wall assessment with GPR technique-a case study" Journal of Applied Geophysics, 56, pp.31-40.

[33] Cassidy, N., Eddies, R. and Dods, S. (2011) "Void detection beneath reinforced concrete sections: The practical application of ground-penetrating radar and ultrasonic techniques" Journal of Applied Geophysics, 74:4, pp.263-276. 